\title{
Bringing back the giants: juvenile Tridacna gigas from natural spawning of restocked giant clams
}
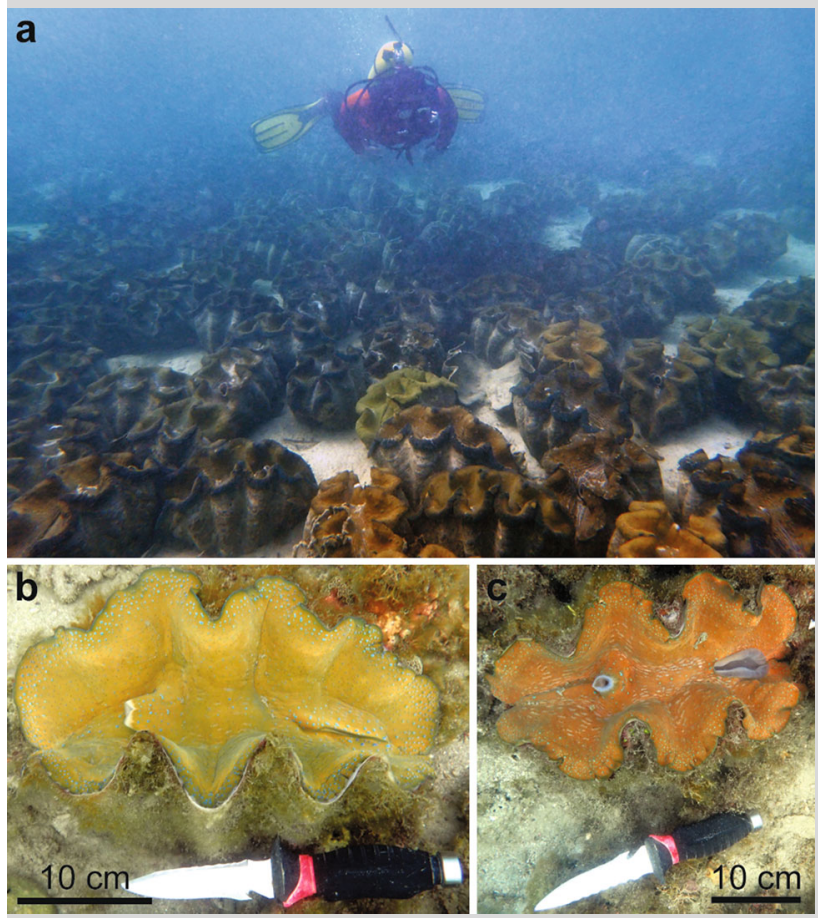

Fig. 1 a Adult giant clams at the ocean nursery on Silaqui Island, Bolinao, Philippines. b, c Juvenile natural recruits discovered at the nearby restocking site in Caniogan, Anda
Coral reef ecosystems are in rapid decline stemming from the effects of local human activities exacerbated by climate change. This has resulted in declining populations of many species, including the true giant clam, Tridacna gigas (MingoaLicuanan and Gomez 2002). Giant clams are especially vulnerable to extirpation because of their economic potential (Neo et al. 2015). Of all the tridacnine species, $T$. gigas is the most critically endangered and is locally extinct in many parts of its natural range.

Since 1985, the Bolinao Marine Laboratory of the University of the Philippines has been culturing giant clams to replenish locally extinct populations in the Philippines. More than 20,000 T. gigas and 50,000 individuals of other tridacnine species have been restocked at more than 40 sites around the country (Gomez and Mingoa-Licuanan 2006). Giant clams restocked more than $10 \mathrm{yr}$ ago have potentially reached reproductive maturity. Here we report the first recorded sighting of juvenile T. gigas at Caniogan, Anda, a few hundreds of meters from the closest restocking site and 10-20 km from the Silaqui Island ocean nursery (Fig. 1a) and the Hundred Islands National Park, two sites with the largest restocked populations of tridacnines in northwestern Philippines. The juveniles are about $29 \mathrm{~cm}$ in shell length and are estimated to be around 2 yr old (Fig. 1b, c). These juveniles likely resulted from natural spawning of restocked individuals, and their distance from restocking sites signifies the dispersal potential of spawned larvae.

The discovery of juvenile $T$. gigas indicates that restocked individuals can potentially replenish local populations. This marks an achievement for the Philippine giant clam conservation effort. However, it should be emphasized that continued success of the program requires a strong commitment from local communities to protect restocking sites. Further observation of recruits is needed to determine the full impact of the giant clam conservation program in the Philippines.

Acknowledgements The authors acknowledge Edgardo D. Gomez for his guidance on this study and Ronald De Guzman and Michael Angelou Nada for field observations. This work was funded by the Marine Science Institute, University of the Philippines. PCC was supported by the National Geographic Society (ASIA-08-15).

\section{References}

Gomez ED, Mingoa-Licuanan SS (2006) Achievements and lessons learned in restocking giant clams in the Philippines. Fish Res 80:46-52 Mingoa-Licuanan SS, Gomez ED (2002) Giant clam conservation in Southeast Asia. Tropical Coasts 3:24-56

Neo ML, Eckman W, Vicentuan K, Teo SLM, Todd PA (2015) The ecological significance of giant clams in coral reef ecosystems. Biol Conserv 181:111-123

P. C. Cabaitan · C. Conaco ( $\square)$

Marine Science Institute, University of the Philippines, Diliman, 1101 Quezon City, Philippines

e-mail: cconaco@msi.upd.edu.ph

Received: 20 December 2016/Accepted: 10 February 2017/Published online: 16 February 2017

Coral Reefs (2017) 36:519

(C) Springer-Verlag Berlin Heidelberg 2017 